\title{
Investigating the inflammatory cascade effect of basophil activation in children with allergic rhinitis or asthma, via the IgE-FcERI-NF-KB signaling pathway
}

\author{
Yi Qiao ${ }^{A-F}$, Jie Chen ${ }^{A-C, E, F}$ \\ A - research concept and design; $\mathrm{B}$ - collection and/or assembly of data; $\mathrm{C}$ - data analysis and interpretation; \\ $D$ - writing the article; $E$ - critical revision of the article; $F$ - final approval of the article
}

Department of Otorhinolaryngology, National Children's Medical Center, Shanghai Children's Medical Center, Shanghai Jiao Tong University School of Medicine, China

Address for correspondence

Jie Chen

E-mail: hwen9308588@sina.com

Funding sources

None declared

Conflict of interest

None declared

Received on June 9, 2020

Reviewed on June 11, 2020

Accepted on April 13, 2021

Published online on June 11, 2021

Cite as

Qiao Y, Chen J. Investigating the inflammatory cascade effect of basophil activation in children with allergic rhinitis or asthma, via the lgE-FcERl-NF-KB signaling pathway. Adv Clin Exp Med. 2021;30(7):673-679.

doi:10.17219/acem/135756

DOI

10.17219/acem/135756

Copyright

Copyright by Author(s)

This is an article distributed under the terms of the

Creative Commons Attribution 3.0 Unported (CC BY 3.0)

(https://creativecommons.org/licenses/by/3.0/)

\begin{abstract}
Background. Allergic rhinitis (AR) is a type I allergic reaction mediated by serum immunoglobulin $\mathrm{E}(\mathrm{lg} \mathrm{E})$.

Objectives. This study aimed to investigate the basophil activation rate and serum expression of inflammatory factors in AR patients and rats. The involvement of the lgE-FcERl-nuclear factor kappa B (NF-KB) signaling pathway in the pathogenesis of AR was also explored.
\end{abstract}

Materials and methods. Thirty patients with pediatric AR (or asthma; untreated) were enrolled in our hospital as the observation group. Fifteen healthy children were selected as the control group. The basophil activation and serum levels of interleukin (IL)-4, IL-5, IL-13, lgE, and prostaglandin D2 (PGD2) in 2 groups of children were detected. Forty-eight male Sprague Dawley rats were randomly divided into group A (AR model group), group B (AR model + lgE inhibitor), group C (AR model + omalizumab), and group D (control). The animal model was established by intraperitoneal injection of ovalbumin and nasal mucosa stimulation. The basophil activation rate, serum levels of IL-4, IL-5, IL-13, IgE, and PGD2 were analyzed.

Results. In children with AR, the blood samples contained mainly activated basophils, whereas the healthy group showed mainly non-activated basophils. The levels of $I L-4, I L-5, I L-13, \lg E$ and PGD2 in the serum of the AR group were higher than those in healthy subjects $(p<0.05)$. In animal studies, the blood samples collected from group A were mainly activated basophils, while the samples of the other groups were mainly non-activated basophils. The serum contents of IL-4, IL-5, IL-13, IgE, and PGD2 in group A were significantly higher than those in groups $B$ and $C(p<0.05)$.

Conclusions. Patients with AR showed increased activation of basophils and elevated expression of IL-4, $\| L-5, I L-13, \operatorname{lgE}$, and PGD2. The upregulation of F(ER/ and NF-KB was involved in the pathogenesis of AR.

Key words: allergic rhinitis, basophil, lgE-FcERI-NF-kB 


\section{Background}

Allergic rhinitis (AR) is caused by the release of histamine, mediated by serum immunoglobulin E (IgE), after exposure to allergens. A variety of immune cells and cytokines participate in the reaction. ${ }^{1}$ The main clinical manifestations are sneezing, nasal itching and nasal mucosal swelling. ${ }^{2}$ The pathogenesis of AR is complex, and is mainly associated with $\mathrm{T}$ lymphocyte and B lymphocyte disorders, such as Th2, which plays an important role in the occurrence and development of AR. ${ }^{3}$ In recent years, the incidence of AR has increased year by year. Compared with adults, children have a higher prevalence, and AR accounts for the majority of outpatient visits in children globally. ${ }^{4}$ According to statistics, the prevalence of AR in China is as high as $11.25 \%$, and that of children under 3 years of age is as high as $20 \%$. The clinical strategy of AR mainly involves anti-allergic treatment, but the clinical efficacy is not good. ${ }^{5}$

Toll-like receptors (TLRs) are widely involved in the occurrence and development of AR. Among them, activating the MyD88 dependent or independent pathways of TLRs to induce an inflammatory response is the main mechanism for the pathogenesis of AR. Both pathways activate nuclear factor kappa $\mathrm{B}(\mathrm{NF}-\mathrm{k} \mathrm{B}){ }^{6-8}$ It is a transcription factor located in the downstream signaling pathway hub of TLR. It plays a pivotal role in inflammation and the immune response by regulating a cascade amplification cascade effect between immune and inflammatory related factors and inflammatory transmitters. The main form of NF-kB is the heterodimer, composed of P50 and p65. Normally, NF- $\mathrm{kB}$ binds with its inhibitor protein (I-kB) to form an inactive trimer, which is mainly confined to the cytoplasm to prevent nuclear uptake of NF-kB. ${ }^{9}$ However, in stress and inflammatory reaction, cytokines and other factors can phosphorylate, ubiquitinate and degrade I-kappa B through one or more signaling pathways, release NF- $\mathrm{B}$, then transfer free NF-kB to the nucleus, and activate a series of transcriptional procedures of immune-related genes to increase their expression, thus promoting large-scale inflammatory cell infiltration and degradation. They aggregate in inflammatory sites, causing or further aggravating inflammatory reactions. ${ }^{10-12}$ FceRI is a high-affinity receptor of IgE and plays an important role in IgE-mediated allergic reaction. It is composed of gamma chains of a homologous dimer structure connected by alpha chains, beta chains and disulfide bonds. It exists in the form of a trimer $\left(\alpha \gamma_{2}\right)$ and tetramer $\left(\alpha \beta \gamma_{2}\right)$ in the human body. It has been found that many kinds of cells in vivo, such as eosinophils, mast cells, basophils, and dendritic cells, all express FceRI. It has been confirmed that FceRI, expressed by mast cells and basophils, plays an important role in regulating rapid and delayed allergic reactions in AR patients. ${ }^{13}$ This study explored the expression of IgE, FceRI and NF- $\mathrm{kB}$ in AR, and provides new ideas and an experimental basis for the prevention and treatment of AR.

\section{Objectives}

This study aimed to investigate the basophil activation rate and serum expression of inflammatory factors in AR patients and rats. The involvement of the IgE-FceRINF- $\mathrm{kB}$ signaling pathway in the pathogenesis of AR was also explored.

\section{Materials and methods}

\section{Patients}

This observational study included 30 children with AR or asthma (untreated) in Shanghai Children's Medical Center who were collected as observation group, and 15 healthy children who were selected as control group. The diagnosis of AR and asthma followed the "Guidelines for diagnosis, prevention and treatment of bronchial asthma in children"14 and the "Guidelines for the diagnosis and treatment of AR"15 by the Chinese Medical Association, respectively. Patients with other types of rhinitis, immune system diseases, infection within 3 months prior to the start of the study, or with long-term use of hormones and drugs were excluded; all the children from the study group met the diagnostic criteria of rhinitis. There was no significant difference in age and sex between the 2 groups ( $p>0.05)$. The present study was approved by the ethics committee of the National Children's Medical Center, Shanghai Children's Medical Center, Shanghai Jiao Tong University School of Medicine, China.

\section{Animal study}

Forty-eight SPF male Sprague Dawley D rats (age: 3 months, weight: $180-220 \mathrm{~g}$ ) were purchased from the SJA Laboratory Animal Company (Hunan, China). The animals were randomly divided into 4 groups with 12 rats in each group. In group $A$, a rat model of AR was established by intraperitoneal injection of ovalbumin and sensitization by nasal mucosal stimulation. No treatment was given after the model was successfully established. In group B, the IgE inhibitor E2_79 (Sigma-Aldrich, St. Louis, USA), which prevents binding of free IgE to FceRI was given on the basis of model group. In group C, Omalizumab (Sigma-Aldrich), a recombinant DNA-derived humanized IgG1k monoclonal antibody that specifically binds to free human IgE, was injected into the tail vein on the basis of model group. In group D, a nasal drip was applied with an equivalent amount of saline as the treatment. The animal study was approved by the laboratory animal approval center of the National Children's Medical Center, Shanghai Children's Medical Center, Shanghai Jiao Tong University School of Medicine. 


\section{Whole body sensitization}

In addition to group $\mathrm{D}$, which received saline only, the other 3 groups were treated with $0.3 \mathrm{mg}$ of ovalbumin as an antigen, $30 \mathrm{mg}$ of as an adjuvant and $1 \mathrm{~mL}$ of saline as a suspension, and then given intraperitoneal injection, once every other day, 7 injections in total (the whole treatment lasted 14 days).

\section{Local stimulation and intensified sensitization}

After the immune phase of intraperitoneal injection was complete, from the $15^{\text {th }}$ day, the bilateral nasal cavity was stimulated locally with a $10 \mathrm{UL}$ nasal drip of normal saline solution containing $5 \%$ ovalbumin, once a day for 7 days. In the control group (D), this replaced by the same dose of normal saline.

\section{Blood samples}

Venous blood $(2 \mathrm{~mL})$ was extracted from the fasting children with a serum separating tube in the morning. The blood of each group of rats was collected from the eyeball and tail vein 14 days after treatment. The serum samples were separated using centrifugation. Basophils were separated with Percoll gradient centrifugation to reflect the activation rate of basophils. The contents of interleukin (IL)-4, IL-5, IL-13, IgE, and prostaglandin D2 (PGD2) in the serum of the children were detected with enzyme-linked immunosorbent assay (ELISA) using commercial kits (IL-4 cat. No. ab100770, IL-5 cat. No. ab267811, IL-13 cat. No. ab269547, IgE cat. No. ab157736; all from Abcam, Cambridge, USA; and PGD2 from Abbexa cat. No. abx150372; Abbexa, Cologne, Germany). Pearson correlation analysis was performed

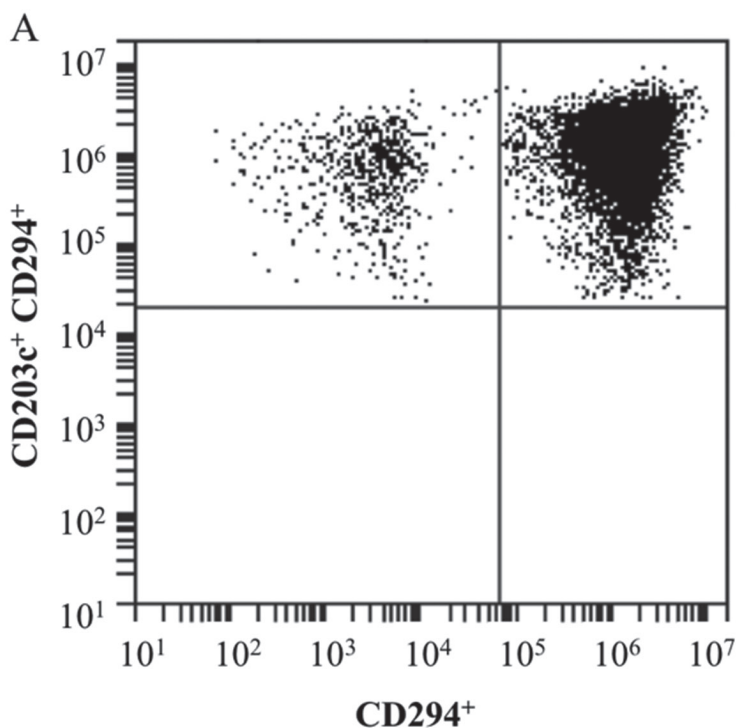

to determine the correlation between basophil activation and the serum level of IgE. Basophils in mouse blood samples and the serum expressions of FceRI and nuclear protein NF- $\mathrm{kB}$ were analyzed using western blot.

\section{Western blotting}

For western blotting, the extracted proteins were loaded on SDS-PAGE and transferred to polyvinylidene fluoride (PVDF) membranes. The membranes were then incubated with the primary antibodies of anti-NF- $\mathrm{KB}$ (ab209795; Abcam) and anti-FceRI (ab229889; Abcam) followed by a conjugated secondary antibody. The films were scanned following with the EasySee Western Blot Kit (Beijing TransGen Biotech, Beijing, China).

\section{Statistical analyses}

The SPSS v. 18.0 statistical software (SPSS Inc., Chicago, USA) was used to process and analyze the data, and the measurement data were described as mean \pm standard deviation (SD). Univariate analysis of variance (ANOVA) was used for multi-group comparison; we also conducted correlation analysis. Comparison between 2 groups was performed using Student's t-test and $x^{2}$ tests were conducted for rates. A value of $\mathrm{p}<0.05$ was considered statistically significant.

\section{Results}

\section{Activation rate of basophils in different groups}

Figure 1A shows the activation rate of basophils in patients with AR, and Fig. 1B shows the activation rate

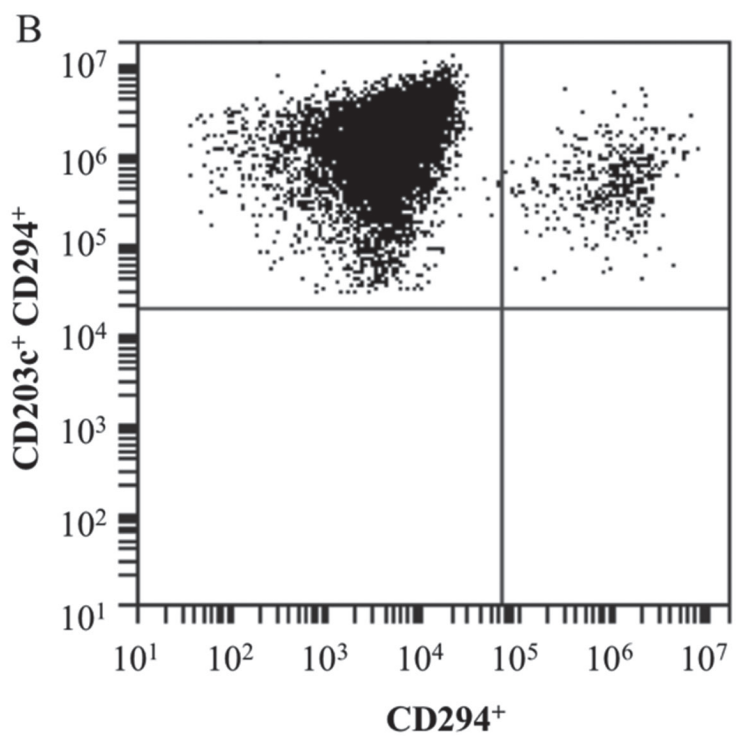

Fig. 1. Activation rate of basophils in different groups. A. Activated and inactivated basophils in AR patients; B. Activated and inactivated basophils in the control group 

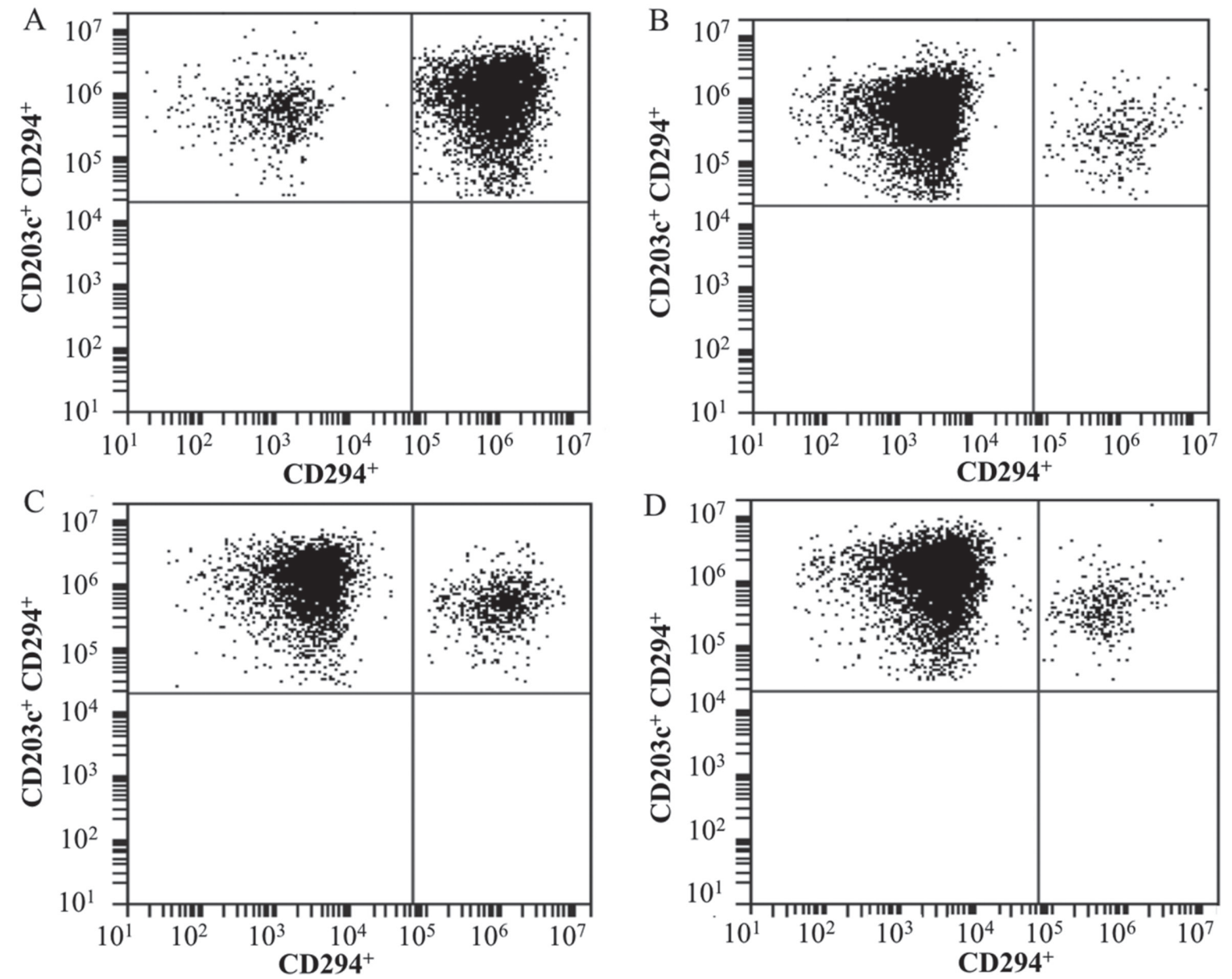

Fig. 2. Activation rate of basophils in blood samples of rats in each group. Activated and inactivated basophils in animals of the AR model group (A), the IgE inhibitor E2_79 group (B), the Omalizumab group (C), and the control group (D)

of basophils in normal subjects. The cells in the upper left corner represent the inactivated basophils, while those in the upper right corner represent the activated basophils. In AR patients, the rate of cell activation (91.10\%) was significantly higher than that in the control group $(6.10 \%)(\mathrm{p}<0.05$; Table 1). No significant difference was found for age and sex. In the animal study, the rate of activated basophils in group A $(91.10 \%)$ was also significantly higher than in treatment groups B (3.60\%) and C (8.40\%) and in the control group D (7.10\%) ( $<<0.05$; Fig. 2A and Table 2).

\section{Comparison of the contents of IL-4, IL-5, IL-13, IgE, and PGD2 in different groups}

Compared with the control group, the levels of serum inflammatory factors IL-4, IL-5 and IL-13 in the observation group were significantly higher ( $<<0.05$; Table 3 ). Compared with the control group, the levels of serum inflammatory factors IgE and PGD2 in the observation group were also significantly higher $(\mathrm{p}<0.05$; Table 4$)$.

The contents of IL-4, IL- 5 and IL-13 in the serum of rats in each group were compared as shown in Table 5. The results of a one-way ANOVA showed that the contents
Table 1. Comparison of activated basophils between the observation and control groups $(X \pm S)$

\begin{tabular}{|l|c|c|}
\multicolumn{1}{|c|}{ Variables } & $\begin{array}{c}\text { Control group } \\
(\mathrm{n}=15)\end{array}$ & $\begin{array}{c}\text { Observation group } \\
(\mathrm{n}=30)\end{array}$ \\
\hline Age [years] & $10.00 \pm 2.59$ & $9.76 \pm 3.34$ \\
\hline Sex (male:female) & $9: 6$ & $17: 13$ \\
\hline CD294+ [\%] & 93.20 & $8.70^{*}$ \\
\hline CD203C+CD294+ $\left.^{+} \%\right]$ & 6.10 & $91.10^{*}$ \\
\hline
\end{tabular}

Compared with the control group; ${ }^{*} p<0.05$. Rates are compared using $x^{2}$ test between the 2 groups.

Table 2. Comparison of activated basophils in rats $(X \pm S)$

\begin{tabular}{|l|c|c|c|}
\hline \multicolumn{1}{|c|}{ Groups } & $\mathrm{n}$ & $\mathrm{CD}_{294^{+}}^{+}[\%]$ & $\mathrm{CD} 203 \mathrm{C}^{+} \mathrm{CD} 294^{+}[\%]$ \\
\hline $\mathrm{A}$ & 12 & 8.90 & 91.10 \\
\hline $\mathrm{B}$ & 12 & $95.70^{*}$ & $3.60^{*}$ \\
\hline C & 12 & $91.10^{*}$ & $8.40^{*}$ \\
\hline $\mathrm{D}$ & 12 & $93.20^{*}$ & $7.10^{*}$ \\
\hline
\end{tabular}

${ }^{*} p<0.05$, compared with group A. Rates are compared using $x^{2}$ test between the 2 groups.

of IL-4, IL-5 and IL-13 were significantly different among different groups ( $\mathrm{p}<0.01$ ). Levels of IL-4, IL-5 and IL-13 were significantly higher in the AR model group A than 
Table 3. Comparison of blood inflammatory factors between 2 groups $(X \pm S)$

\begin{tabular}{|l|c|c|c|c|}
\hline \multicolumn{1}{|c|}{ Groups } & $\mathrm{n}$ & $\mathrm{IL}-4$ [pg/mL] & IL-5 [ng/L] & $6.69 \pm 1.37$ \\
\hline Control group & 15 & $79.81 \pm 23.66$ & $14.05 \pm 4.31^{*}$ \\
\hline Observation group & 30 & $167.27 \pm 37.10^{*}$ & $19.85 \pm 4.84$ \\
\hline
\end{tabular}

Compared with the control group; ${ }^{*} p<0.05$. Comparison between 2 groups was performed using Student's t-test; IL - interleukin.

Table 4. Comparison of IgE and PGD2 in blood between 2 groups $(\mathrm{X} \pm \mathrm{S})$

\begin{tabular}{|l|c|c|c|}
\hline \multicolumn{1}{|c|}{ Groups } & $\mathrm{n}$ & $\mathrm{IgE}[\mathrm{ug} / \mathrm{mL}]$ & PGD2 [ng/L] \\
\hline Control group & 15 & $185.37 \pm 36.07$ & $87.07 \pm 10.62$ \\
\hline Observation group & 30 & $337.60 \pm 73.91^{*}$ & $137.95 \pm 31.81^{*}$ \\
\hline
\end{tabular}

Compared with the control group; * $p<0.05$. Comparison between 2 groups was performed using Student's t-test; lgE - immunoglobulin E; PGD2

- prostaglandin D2.

Table 5. Comparison of rat blood inflammatory factors $I L-4, I L-5$ and $I L-13(X \pm S)$

\begin{tabular}{|c|c|c|c|c|}
\hline Group & $\mathrm{n}$ & IL-4 [pg/mL] & IL-5 [ng/L] & IL-13 [ng/L] \\
\hline Group A & 12 & $147.30 \pm 20.77$ & $14.02 \pm 2.21$ & $20.37 \pm 2.27$ \\
\hline Group B & 12 & $52.78 \pm 23.87$ & $6.49 \pm 2.02$ & $6.69 \pm 2.71$ \\
\hline Group C & 12 & $44.28 \pm 24.85$ & $4.98 \pm 2.36$ & $8.87 \pm 3.49$ \\
\hline Group D & 12 & $6.12 \pm 3.71$ & $7.73 \pm 2.45$ & $3.12 \pm 1.15$ \\
\hline F-value & - & 105.80 & 36.88 & 102.70 \\
\hline $\mathrm{p}$-value & - & $<0.001$ & $<0.001$ & $<0.001$ \\
\hline
\end{tabular}

The p-values and F-values were obtained by comparison among 3 or more groups using one-way analysis of variance (ANOVA); IL - interleukin.

in treatment groups $\mathrm{B}$ and $\mathrm{C}$ and the control group $\mathrm{D}$ $(\mathrm{p}<0.01$, Table 5). No significant difference was found between groups B and C ( $>0.05)$.

\section{Comparison of the levels of inflammatory factors IgE and PGD2 in blood samples of rats in each group}

The comparative results of serum IgE and PGD2 levels among groups are shown in Table 6 . The results of a oneway ANOVA of IgE and PGD2 showed that there were significant differences in the contents of IgE and PGD2 among different groups $(\mathrm{p}<0.01)$. The results of LSD showed that the levels of IgE and PGD2 in group A were significantly higher than those in group $B, C$ and $D(p<0.01)$, and there was no significant difference between group $B$ and group $C$ $(\mathrm{p}>0.05)$.

\section{Expression of basophil surface receptor FceRI and nuclear protein NF-KB in blood samples of rats in each group}

As shown in Fig. 3, the basophil surface receptor FceRI and nucleoprotein NF- $\mathrm{kB}$ in group A were remarkably higher than in the control group D, and both treatments (group B and C) markedly decreased protein levels $(\mathrm{p}<0.05)$.

\section{Discussion}

The AR is a type I allergic reaction mediated by $\operatorname{IgE}$ antibody and infiltrated by eosinophils. An imbalance of T helper type 1 or type 2 (Th1/Th2) cytokines is involved in the pathogenesis of AR, which leads

Table 6. Comparison of inflammatory factors IgE and PGD2 in blood samples of rats in each group $(X \pm S)$

\begin{tabular}{|c|c|c|c|}
\hline Group & $\mathrm{n}$ & $\lg E[\mu \mathrm{g} / \mathrm{mL}]$ & PGD2 [ng/L] \\
\hline Group A & 12 & $177.80 \pm 24.69$ & $223.72 \pm 16.56$ \\
\hline Group B & 12 & $68.40 \pm 35.66$ & $69.24 \pm 15.04$ \\
\hline Group C & 12 & $65.98 \pm 32.43$ & $75.36 \pm 16.32$ \\
\hline Group D & 12 & $13.21 \pm 3.44$ & $18.56 \pm 2.17$ \\
\hline $\mathrm{F}$ & - & 77.97 & 486.3 \\
\hline$p$-value & - & $<0.001$ & $<0.001$ \\
\hline
\end{tabular}

IgE - immunoglobulin E; PGD2 - prostaglandin D2. 

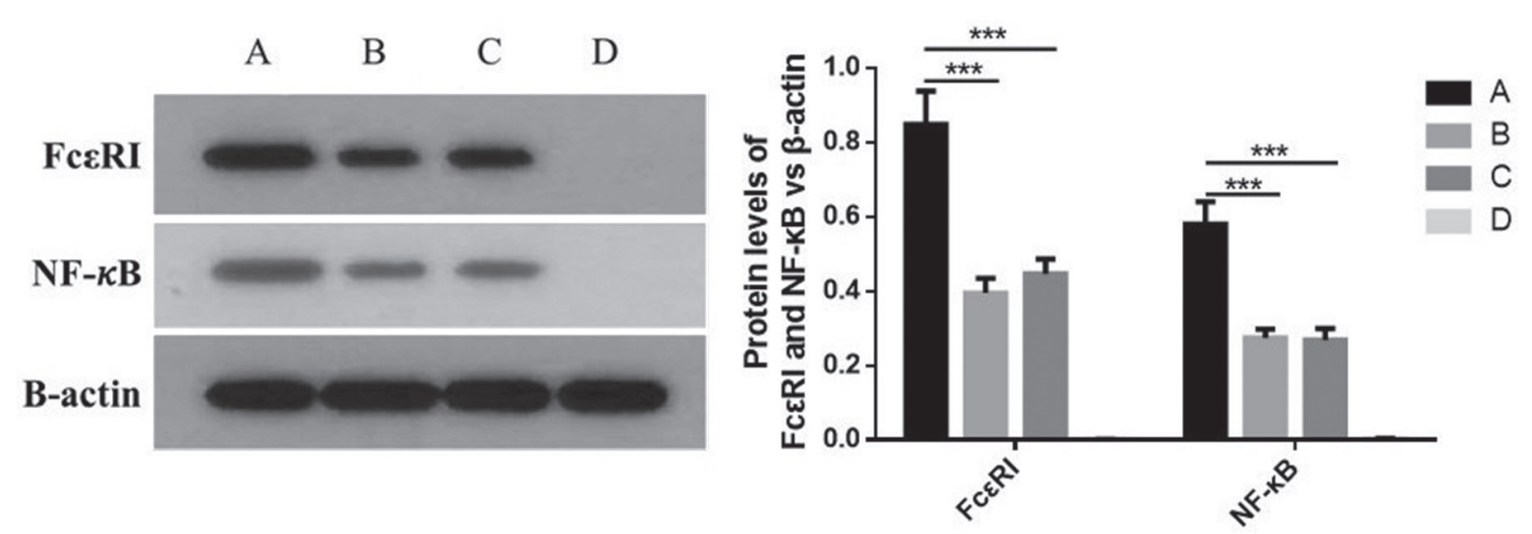

Fig. 3. Expression of basophil surface receptor FceRl and nuclear protein $\mathrm{NF}-\mathrm{KB}$ in rats of each group ${ }^{* * *} p<0.001$ to the overproduction and release of histamine. A large number of inflammatory factors and immunoreactive cytokines participate in the regulation of chronic inflammatory responses in nasal mucosa. ${ }^{16}$ The Th1 cells mainly secrete interferon gamma (IFN- $\gamma$ ) and IL-2. Interferon gamma is a multifunctional protein that can effectively antagonize the synthesis and secretion of IgE, mediated by IL-4, and serves as a protective factor of AR. Interleukin 4 is the main cytokine secreted by Th2 cells, which can stimulate B cells to secrete and release IgE into the blood, thus promoting the combination of allergens and the corresponding receptors on mast cells, resulting in degranulation and the increase of inflammatory transmission. Some studies have shown that the immune activity of Th2 cells is excessively increased during the course of AR. The Th2 cells infiltrated nasal mucosa, and the serum levels of IL-4, IL-5 and IL-13 were significantly increased. In this study, we showed that the expression levels of IL-4, IL-5, IL-13, IgE, and PGD2 inflammatory factors in the serum of the observation group were significantly higher than those in the control group ( $\mathrm{p}<0.05)$.

Studies have shown that NF-kB plays an important role in the pathogenesis of AR by stimulating the CAMP-PKA signaling pathway, promoting ICAM-1 transcription ${ }^{17}$ and inducing the release of inflammatory factors such as mast cells. ${ }^{18}$ Activation of NF-kB can regulate the release of Th cytokines, interfere with the balance of Th1/Th2 cytokines and participate in the physiological and pathological processes of immunity, inflammation and development. The increase of serum IgE level in AR patients was related to the increased number of eosinophils. ${ }^{19}$ As a high affinity receptor of IgE, the expression level of FceRI may be closely related to the development of AR disease. It has been reported that the expression of FceRI in eosinophils is associated with allergic eosinophilic gastroenteritis. ${ }^{20}$ These results suggest that eosinophils expressing FceRI may be involved in the pathogenesis of allergic diseases. However, follow-up studies also found that FceRI was highly expressed in the eosinophils of patients with allergic esophagitis and reflux esophagitis ${ }^{21}$ compared with healthy people. A high expression of FceRI in dendritic cells was also observed in both chronic obstructive pulmonary disease (COPD) and asthma patients. ${ }^{22}$ These data suggest that the increase of FceRI in some cells may be related to a variety of inflammatory diseases.

Our results show that AR patients had increased amount of activated basophils, elevated expressions of IL-4, IL-5, IL-13, IgE, and PGD2, and upregulated levels of FceRI and nuclear protein NF-kB. Also, the levels of IL-4, IL-5, IL-13, IgE, and PGD2 in AR rats were significantly higher than those in the IgE inhibitors and omalizumab groups. There was no significant difference in the levels of IL-4, IL-5, IL-13, IgE, and PGD2 between the IgE inhibitors and omalizumab groups. In addition, the IgE inhibitors and omalizumab groups showed decreased expression of FceRI and nucleoprotein NF-kB on the basophilic granulocyte surface, reduced levels of serum IgE, and downregulated serum levels of IL-4, IL-5, IL-13 and PGD2. It is suggested that IgE, FceRI and NF-kB play an important role in the pathogenesis of AR.

\section{Limitations}

The present study has some limitations. The blood sample size of AR patients is limited, and we have yet to establish the underlying molecular mechanisms, such as the downstream and upstream genes and proteins for IgE-FceRI-NF- $\mathrm{kB}$ signaling during the AR process. All of these elements need more research to confirm.

\section{Conclusions}

This study found that activated basophils were predominant in the blood samples of AR patients and animal models when compared to controls. Moreover, the serum levels of IL-4, IL-5, IL-13, IgE, and PGD2 in children with AR and $A R$ rat model were significantly higher than those in the healthy group. The upregulation of FceRI and NF-kB might be involved in the pathogenesis of AR.

\section{ORCID iDs}

Yi Qiao (D) https://orcid.org/0000-0001-7032-1385

Jie Chen (D) https://orcid.org/0000-0002-9888-9930 


\section{References}

1. Ross SM. Allergic rhinitis: A proprietary extract of Pines pinaster Aiton (pycnogenol) is found to improve the symptoms associated with allergic rhinitis. Holist Nurs Pract. 2016;30(5):301-304. doi:10.1097/ HNP.0000000000000170

2. Wheatley LM, Togias A. Allergic rhinitis. N Engl J Med. 2015;372(5): 456-463. doi:10.1056/NEJMcp1412282

3. De Shazo RD, Kemp SF. Pathogenesis of allergic rhinitis (rhinosinusitis). https://www.uptodate.com/contents/pathogenesis-of-allergicrhinitis-rhinosinusitis. Updated April 9, 2021.

4. Kim HK, Kook JH, Kang KR, Oh DJ, Kim TH, Lee SH. Increased expression of the aryl hydrocarbon receptor in allergic nasal mucosa, contributing to chemokine secretion in nasal epithelium. Am J Rhinol Allergy. 2016;30(4):e107-e112. doi:10.2500/ajra.2016.30.4311

5. Thanaviratananich S, Cho SH, Ghoshal AG, et al. Burden of respiratory disease in Thailand: Results from the APBORD observational study. Medicine (Baltimore). 2016;95(28):e4090. doi:10.1097/MD.000000000 0004090

6. Kawasaki T, Kawai T. Toll-like receptor signaling pathways. Front Immunol. 2014;5:461. doi:10.3389/fimmu.2014.00461

7. Nardo DD. Toll-like receptors: Activation, signalling and transcriptional modulation. Cytokine. 2015;74(2):181-189. doi:10.1016/j.cyto. 2015.02.025

8. Deguine J, Barton GM. MyD88: A central player in innate immune signaling. F1000Prime Rep. 2014;6:97. doi:10.12703/P6-97

9. Coimbra R, Melbostad H, Loomis W, et al. LPS-induced acute lung injury is attenuated by phosphodiesterase inhibition: Effects on proinflammatory mediators, metalloproteinases, NF-kappaB, and ICAM-1 expression. J Trauma. 2006;60(1):115-125. doi:10.1097/01.ta.000020 0075.12489 .74

10. Ma J, Liang $H$, Jin HR, et al. Yangonin blocks tumor necrosis factora-induced nuclear factor-KB-dependent transcription by inhibiting the transactivation potential of the RelA/p65 subunit. JPharmacol Sci. 2012;118(4):447-454. doi:10.1254/jphs.11215fp

11. Liu S, Misquitta YR, Olland A, et al. Crystal structure of a human I kappa B kinase beta asymmetric dimer. J Biol Chem. 2013;288(31):22758-22767. doi:10.1074/jbc.M113.482596

12. Hochrainer K, Racchumi G, Anrather J. Site-specific phosphorylation of the $\mathrm{p} 65$ protein subunit mediates selective gene expression by differential NF-KB and RNA polymerase II promoter recruitment. J Biol Chem. 2013;288(1):285-293. doi:10.1074/jbc.M112.385625
13. Kraft S, Kinet JP. New developments in FcepsilonRI regulation, function and inhibition. Nat Rev Immunol. 2007;7(5):365-378. doi:10.1038/ nri2072

14. Hong J, Bao Y, Chen A, et al. Chinese guidelines for childhood asthma 2016: Major updates, recommendations and key regional data. J Asthma. 2018;55(10):1138-1146. doi:10.1080/02770903.2017.1396474

15. Cheng $\mathrm{L}$, Chen J, Fu Q, et al. Chinese society of allergy guidelines for diagnosis and treatment of allergic rhinitis. Allergy Asthma Immunol Res. 2018;10(4):300-353. doi:10.4168/aair.2018.10.4.300

16. Kim EH, Yang L, Ye $P$, et al. Long-term sublingual immunotherapy for peanut allergy in children: Clinical and immunologic evidence of desensitization. J Allergy Clin Immunol. 2019;144(5):1320-1326.e1. doi:10.1016/j.jaci.2019.07.030

17. Wang SZ, Ma FM, Zhao JD. Expressions of nuclear factor-kappa B p50 and p65 and their significance in the up-regulation of intercellular cell adhesion molecule-1 mRNA in the nasal mucosa of allergic rhinitis patients. Eur Arch Otorhinolaryngol. 2013;270(4):1329-1334. doi:10.1007/s00405-012-2136-y

18. Kim HI, Hong SH, Ku JM, et al. Tonggyu-tang, a traditional Korean medicine, suppresses pro-inflammatory cytokine production through inhibition of MAPK and NF-KB activation in human mast cells and keratinocytes. BMC Complement Altern Med. 2017;17(1):186. doi:10.1186/ s12906-017-1704-5

19. Demirjian M, Rumbyrt JS, Gowda VC, Klaustermeyer WB. Serum IgE and eosinophil count in allergic rhinitis: Analysis using a modified Bayes' theorem. Allergolol Immunopathol (Madr). 2012;40(5):281-287. doi:10.1016/j.aller.2011.05.016

20. DehlinkE, Fiebiger E. The role of the high-affinity lgE receptor, FcepsilonRI, in eosinophilic gastrointestinal diseases. Immunol Allergy Clin North Am. 2009;29(1):159-170. doi:10.1016/j.iac.2008.09.004

21. Yen EH, Hornick JL, Dokter M, et al. Comparative analysis of FcعRI expression patterns in patients with eosinophilic and reflux esophagitis. Gastroenterology. 2010;136(5):A-278. doi:10.1097/MPG. 0b013e3181de7685

22. Stoll $P$, Bähker $A$, Ulrich $M$, et al. The dendritic cell high-affinity lgE receptor is overexpressed in both asthma and severe COPD. Clin Exp Allergy. 2016;46(4):575-583. doi:10.1111/cea.12664 